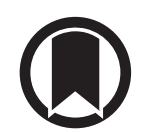

CrossMark

\section{Regional differences in rate of FEV1 decline in COPD: lessons from SUMMIT}

\author{
To the Editor:
}

A publication by ZHou et al. [1], who studied 841 patients from China with mild to moderate chronic obstructive pulmonary disease (COPD) (Global Initiative for Chronic Obstructive Lung Disease (GOLD) stage I and II) for 2 years, documented a $22 \mathrm{~mL}$ per year beneficial effect of tiotropium compared with placebo on rate of forced expiratory volume in $1 \mathrm{~s}$ (FEV1). This effect was over three times larger than the $6 \mathrm{~mL}$ per year (95\% CI 1 to $11 \mathrm{~mL}$ per year) reported by DeCRAMER et al. [2] in the 2739 GOLD stage II patients from the 4-year UPLIFT trial. We hypothesised that the large difference in results in patients with COPD with similar degree of airflow limitation at study entry could be related to regional differences in response to similar pharmacological treatment. To test this hypothesis, we investigated the regional differences in FEV1 decline in patients in the COPD Study to Understand Mortality and MorbidITy (SUMMIT), all of whom had spirometric GOLD stage II COPD at enrolment [3].

In SUMMIT, we investigated whether the inhaled corticosteroid fluticasone furoate $100 \mu \mathrm{g}(\mathrm{FF})$, the long-acting beta-agonist vilanterol $25 \mu \mathrm{g}$ (VI) or the combination (FF/VI) impacted on mortality. The results from this event-driven study failed to show a benefit of any of the medications on risk of death compared with placebo [3]. In addition, and as secondary pre-specified outcome, spirometry was measured every 12 weeks. Results of the effect of therapy on lung function decline for the whole SUMMIT cohort has been published [4], which included 15457 patients with an average of seven spirometry assessments who were followed for an average of 1.7 years. This did not compare regional differences, so here we have performed a post hoc analysis using the same methods but with subjects divided into Asia and non-Asia subgroups. We present only patients taking placebo or FF/VI for brevity.

In SUMMIT, there were 1337 patients randomised to placebo or FF/VI in the Asia subgroup (China, Indonesia, India, Japan, Korea, Malaysia, Philippines, Taiwan, Thailand and Vietnam), of which 253 were from China. As shown in table 1, the rate of FEV1 decline in this subgroup was $16 \mathrm{~mL}$ per year (95\% CI -1 to $34 \mathrm{~mL}$ per year), slower on active FF/VI therapy than on placebo. This value is close to that reported by ZHOU et al. [1] in their study, which was $22 \mathrm{~mL}$ per year (95\% CI 6 to 37) favouring tiotropium over placebo. In contrast, in the 8232 patients that were not from Asia studied in SUMMIT, a $7 \mathrm{~mL}$ per year (95\% CI -1 to $14 \mathrm{~mL}$ per year) difference was seen for FF/VI versus placebo.

Table 1 also shows that this regional effect remains when the values are expressed as per cent predicted FEV1 in both the ZHou et al. [1] and SUMMIT Asia subpopulations. In the former study, a difference of $0.9 \%$ per year was seen for tiotropium versus placebo. In the SUMMIT Asia subgroup, this was $0.7 \%$ per year ( $95 \%$ CI -0.1 to $1.4 \%$ per year), whereas in the non-Asian SUMMIT patients taking FF/VI had a slower decline of $0.2 \%$ per year ( $95 \%$ CI 0.0 to $0.5 \%$ per year) compared with placebo.

To our knowledge, no study has reported the potential effect of regional response to medications as a possible determinant of lung function decline. The results observed suggests that there are regional differences in the response to pharmacotherapy. In the patients recruited in China by ZHou et al. [1] and in Asia in SUMMIT (table 1), the effect of pharmacotherapy, independent of the medication used, was at least double of that observed in non-Asian countries.

One potential explanation is that the patients had higher baseline FEV 1 value in $\mathrm{mL}$ in the ZHou et al. [1] cohort compared with the patients recruited in SUMMIT. However, the absolute rate of decline in the

@ERSpublications

This analysis of FEV1 decline in patients who enrolled with spirometric GOLD stage II COPD (SUMMIT) showed regional differences in therapeutic response. Such variation should be considered when comparing pharmacotherapies across different global areas. http://bit.ly/2YwMIgW

Cite this article as: Celli BR, Anderson JA, Brook RD, et al. Regional differences in rate of FEV 1 decline in COPD: lessons from SUMMIT. Eur Respir J 2019; 53: 1900278 [https://doi.org/10.1183/ 13993003.00278-2019]. 
TABLE 1 Clinical characteristics and lung function decline in Asians compared with non-Asians in two different pharmacological trials

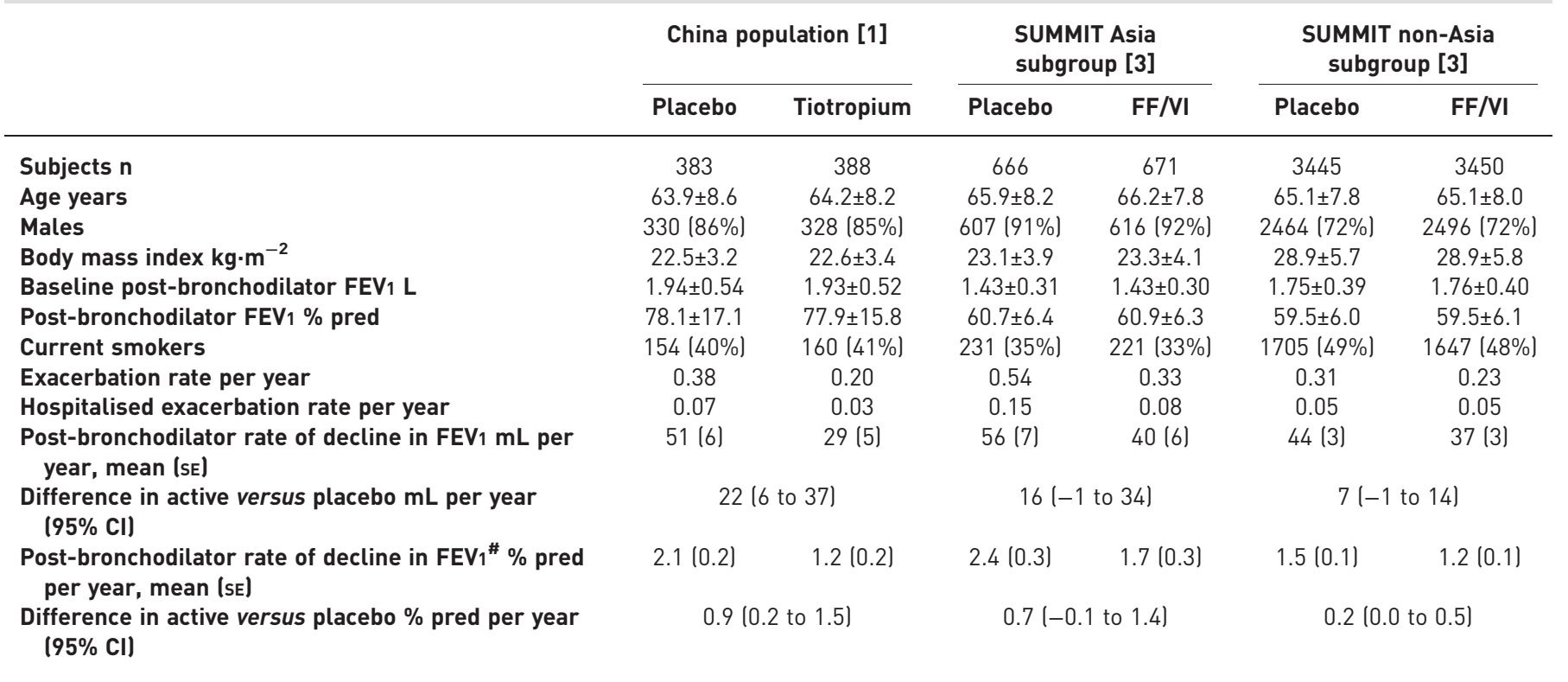

Data are presented as mean \pm SD or $\mathrm{n}(\%)$, unless otherwise stated. FF/VI: combination fluticasone furoate $100 \mu \mathrm{g}$ and vilanterol $25 \mu \mathrm{g}$; FEV 1 : forced expiratory volume in $1 \mathrm{~s} .{ }^{\#}$ : the National Health and Nutrition Examination Survey [5] was used to calculate \% predicted FEV 1 in the SUMMIT study. Data on lung function decline for the SUMMIT cohort are from CALVERLEY et al. [4].

placebo group in the SUMMIT Asian population (table 1) was, if anything, higher (56 mL per year) than that of the placebo group in the Zhou study $(51 \mathrm{~mL}$ per year). Further, when expressed as a proportion of FEV1 change (to normalise for baseline FEV1 value) the difference still remained between the Asian and the non-Asian groups. It may also be that there were differences in the therapy that patients were receiving at baseline. However, the criteria for inclusion in SUMMIT was similar across regions. In addition, as was true for the study by ZHоu et al. [1], the majority of patients had milder disease for which medications are least used. Other potential reasons such as differences in body mass index or environmental exposure remain to be explored.

We believe these findings are not only interesting but important because regional differences in response to therapy should be taken into account when comparing effects of therapeutic agents in different areas of the world. Why different populations behave in this way merits further study.

These analyses add to the growing evidence that pharmacotherapy does modify lung function progression in COPD and, as such, a nihilistic approach to the benefit of pharmacotherapy is not justified.

Bartolomé R. Celli $\oplus^{1}$, Julie A. Anderson $\oplus^{2}$, Robert D. Brook ${ }^{3}$, Peter M.A. Calverley ${ }^{4}$, Nicholas J. Cowans ${ }^{5}$, Courtney Crim $^{6}$, Fernando Martinez ${ }^{7}$, David E. Newby ${ }^{8}$, Julie Yates ${ }^{6}$ and Jørgen Vestbo ${ }^{9}$

${ }^{1}$ Pulmonary and Critical Care Division, Brigham and Women's Hospital, Harvard Medical School, Boston, MA, USA. ${ }^{2}$ Research and Development, GlaxoSmithKline, Stockley Park, UK. ${ }^{3}$ University of Michigan Health System, Ann Arbor, MI, USA. ${ }^{4}$ Dept of Medicine, Clinical Sciences Centre, University of Liverpool, University Hospital Aintree, Liverpool, UK. ${ }^{5}$ Statistics and Programming, Veramed Ltd, Twickenham, UK. ${ }^{6}$ Research and Development, GlaxoSmithKline, Research Triangle Park, North Carolina, USA. ${ }^{7}$ Division of Pulmonary and Critical Care Medicine, Weill Cornell Medicine, New York, NY, USA. ${ }^{8}$ Centre for Cardiovascular Science, University of Edinburgh, Edinburgh, UK. ${ }^{9}$ Division of Infection, Immunity and Respiratory Medicine, School of Biological Sciences, University of Manchester, and Manchester University NHS Foundation Trust, Manchester Academic Health Sciences Centre, Manchester, UK.

Correspondence: Bartolomé R. Celli, Pulmonary and Critical Care Division, Brigham and Women's Hospital, Harvard Medical School, Boston, MA, USA. E-mail: bcelli@copdnet.org

Received: Feb 082019 | Accepted after revision: March 032019

Support statement: The SUMMIT study (GSK study number 113782; NCT01313676) was funded by GSK. Funding information for this article has been deposited with the Crossref Funder Registry.

Conflict of interest: B.R. Celli reports grants from AstraZeneca, personal fees for consultancy from GlaxoSmithKline, 
Boehringer Ingelheim, AstraZeneca and Novartis, personal fees for travel from GlaxoSmithKline, personal fees for participating in review activities from GlaxoSmithKline, during the conduct of the study; personal fees for consultancy from Boehringer Ingelheim, AstraZeneca, Almirall and Novartis, outside the submitted work. J.A. Anderson is an employee of and owns shares in GSK. R.D. Brook reports personal fees for steering committee work from GSK, during the conduct of the study. P.M.A. Calverley has advised Boehringer Ingelheim, GSK, AstraZeneca and Takeda on the design and conduct of clinical trials and has spoken at meetings sponsored by these companies and by Novartis. He has no stock holdings in any pharmaceutical company or connection with the tobacco industry. N.J. Cowans is employed by Veramed Ltd, a contract research organisation undertaking contracted statistical analyses of respiratory studies funded by GSK. C. Crim is an employee of and owns shares in GSK. F. Martinez reports non-financial support from GSK as sponsor of the parent study; personal fees for organising education from Continuing Education, CME Incite, Annenberg Center for Health Sciences at Eisenhower, Integritas, Paradigm Medical Communications, LLC, PeerVoice, UpToDate, Haymarket Communications, Western Society of Allergy and Immunology, Methodist Hospital, Columbia University, Prime Healthcare Ltd, WebMD, PeerView Network, California Society of Allergy and Immunology, National Association for Continuing Education, Chiesi and Puerto Rico Thoracic Society, personal fees for steering committee work from Forest Laboratories, has participating on an advisory board for Janssen, personal fees for steering committee, data and safety monitoring board and advisory board work, and lecturing from GlaxoSmithKline, personal fees for steering committee and advisory board work, and organising education from Nycomed/Takeda, personal fees for steering committee and advisory board work, and lecturing from AstraZeneca and Boehringer Ingelheim, personal fees for advisory board work from Bellerophon (formerly Ikaria), Genentech, Roche, Sunovion, Theravance and ConCert Pharmaceuticals, personal fees for advisory board work and organising education from Novartis, personal fees for steering committee and advisory board work from Pearl, personal fees for consultancy from InThought, Proterixbio (formerly Bioscale), Unity Biotechnology and Lucid, outside the submitted work. D.E. Newby reports grants and personal fees for steering committee work from GSK, during the conduct of the study. J. Yates is an employee of and owns shares in GSK. J. Vestbo reports personal fees for steering committee work from GlaxoSmithKline, during the conduct of the study; personal fees from for consultancy and lecturing from GlaxoSmithKline, Chiesi Pharmaceuticals, Boehringer Ingelheim, Novartis and AstraZeneca, outside the submitted work.

The SUMMIT trial is a registered clinical trial (NCT01313676). Information on GSK's data sharing commitments and requesting access to anonymised individual participant data and associated documents can be found at www. clinicalstudydatarequest.com

\section{References}

1 Zhou Y, Zhong NS, Li X, et al. Tiotropium in early-stage chronic obstructive pulmonary disease. N Engl J Med 2017; 377: 923-935.

2 Decramer M, Celli B, Kesten S, et al. Effect of tiotropium on outcomes in patients with moderate chronic obstructive pulmonary disease (UPLIFT): a prespecified subgroup analysis of a randomised controlled trial. Lancet 2009; 374: 1171-1178

3 Vestbo J, Anderson JA, Brook RD, et al. Fluticasone furoate and vilanterol and survival in chronic obstructive pulmonary disease with heightened cardiovascular risk (SUMMIT): a double-blind randomised controlled trial. Lancet 2016; 387: 1817-1826

4 Calverley PMA, Anderson JA, Brook RD, et al. Fluticasone furoate, vilanterol and lung function decline in patients with moderate chronic obstructive pulmonary disease and heightened cardiovascular risk. Am J Respir Crit Care Med 2018; 197: 47-55.

5 Hankinson JL, Kawut SM, Shahar E, et al. Performance of American Thoracic Society-recommended spirometry reference values in a multiethnic sample of adults: the multi-ethnic study of atherosclerosis (MESA) lung study. Chest 2010; 137: 138-145. 